\title{
Effects of Low Chloride versus High Chloride Infusion on Glomerular Filtration Rate and Renal Plasma Flow in Healthy Volunteers-A Randomized, Controlled, Crossover Study
}

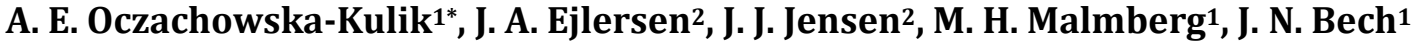 \\ ${ }^{1}$ University Clinic in Nephrology and Hypertension, The Regional Hospital West Jutland, Holstebro and Aarhus University, \\ Aarhus, Denmark \\ ${ }^{2}$ Department of Nuclear Medicine, The Regional Hospital West Jutland, Herning, Denmark \\ Email: ^aocza@hotmail.com, June.Anita.Ejlersen@vest.rm.dk, jjjensen@dadlnet.dk, mymalmbe@rm.dk, \\ Jesper.Noergaard.Bech@vest.rm.dk
}

How to cite this paper: Oczachowska-Kulik, A.E., Ejlersen, J.A., Jensen, J.J., Malmberg, M.H. and Bech, J.N. (2020) Effects of Low Chloride versus High Chloride Infusion on Glomerular Filtration Rate and Renal Plasma Flow in Healthy Volunteers-A Randomized, Controlled, Crossover Study. Open Journal of Nephrology, 10, 73-84.

https://doi.org/10.4236/ojneph.2020.102009

Received: February 3, 2020

Accepted: April 17, 2020

Published: April 20, 2020

Copyright $\odot 2020$ by author(s) and Scientific Research Publishing Inc. This work is licensed under the Creative Commons Attribution International License (CC BY 4.0).

http://creativecommons.org/licenses/by/4.0/

(c) (i) Open Access

\begin{abstract}
Background: Previous studies have shown that chloride liberal fluids may be associated with worse renal outcomes. Deterioration of kidney function during hyperchloremia/chloride overload is believed to be induced by disturbances in renal perfusion, but exact mechanisms of chloride nephrotoxicity are unclear. The purpose of this randomized, crossover study was to investigate the effect of chloride loading on renal plasma flow (RPF), filtration fraction (FF) and glomerular filtration rate (GFR) in order to elucidate potential nephrotoxic mechanisms of chloride infusion. Methods: Fifteen healthy males were investigated twice after treatment with $2 \mathrm{~L}$ isotonic saline and plasma-lyte with a wash-out period of at least 10 days. Within 15 mins after completion of infusion, the kidney parameters (RPF, FF and GFR) were estimated by Technetium-99m diethylenetriamine penta-acetic acid (99-mTc-DTPA) renography. Results: 99-mTc-DTPA renography showed reduction in both mean GFR $(114 \pm 13 \mathrm{ml} / \mathrm{min}$ vs. $119 \pm 12 \mathrm{ml} / \mathrm{min}, p=0.04)$ and RPF $(977 \pm$ $272 \mathrm{ml} / \mathrm{min}$ vs. $1066 \pm 197 \mathrm{ml} / \mathrm{min}, p=0.19)$ and increasing FF ( $12 \% \pm 2 \%$ vs. $11 \% \pm 2 \%, p=0.19$ ) after $0.9 \%$ saline comparing to Plasma-lyte, but only GFR reduction was statistically significant. Reduction in GFR and RPF and increasing in FF after $0.9 \%$ saline was observed in 10 subjects while in 5 others the reverse trend was shown. There were no statistically significant differences between mean systolic and diastolic blood pressure (BP) before and after each infusion except baseline diastolic BP. Weight changes ( $\Delta$ weight)
\end{abstract}


were similar after each infusion. Conclusions: We have demonstrated that high chloride infusion can affect kidney function in healthy subjects and seems to lead to impairment in both RPF and GFR.

\section{Keywords}

Chloride Nephrotoxicity, Renal Plasma Flow, Glomerular Filtration Rate, Renography

\section{Background}

Fluid therapy is widely used in critically ill patients and surgical patients treated in intensive care units (ICU), but the choice of fluid remains controversial. Isotonic sodium chloride with chloride concentration of $154 \mathrm{mmol} / \mathrm{l}$ is the most commonly used crystalloid in ICU. Some studies indicate that chloride overload secondary to large infused volumes of saline leads to hyperchloremia and metabolic acidosis [1] [2]. Both human and animal studies show that hyperchloremia in turn is associated with decreased renal perfusion [3] [4] [5] [6] [7], impaired immune function [8] [9] and increased mortality [10]. Many observational studies show that use of chloride restrictive fluids may be associated with better renal outcomes [11] [12] [13] and decreased risk of death [14] [15] compared with chloride liberal regimes. Large randomized controlled trials show conflicting results [16] [17] [18].

In the light of existing data, deterioration of kidney function during hyperchloremia/chloride overload is believed to be induced by disturbances in renal perfusion, but exact mechanisms of chloride nephrotoxicity are unclear. The purpose of our study was to investigate the effect of chloride loading on renal plasma flow (RPF), filtration fraction (FF) and glomerular filtration rate (GFR) in order to elucidate potential nephrotoxic mechanisms of chloride infusion. We designed a randomized, crossover study to compare the effects of intravenous infusion of $0.9 \%$ saline and Plasma-Lyte on kidney function in healthy subjects using 99mTc-DTPA gamma-camera renography. Renography with 99mTc-DTPA allows simultaneous measurements of RPF, FF and GFR [19] [20]. We aimed to determine whether chloride loading related to use of $0.9 \%$ saline (chloride concentration $=154 \mathrm{mmol} / \mathrm{l}$ ) would affect renal hemodynamic parameters compared to Plasma-lyte (chloride concentration $=98 \mathrm{mmol} / \mathrm{l}$ ).

\section{Materials and Methods}

\subsection{Study Design}

The trial was performed as a randomized, crossover study in healthy subjects. Study intervention was blinded for observers who evaluated renography. Fifteen healthy males were investigated twice after treatment with $2 \mathrm{~L}$ isotonic saline and plasma-lyte with a wash-out period of at least 10 days. 


\subsection{Randomization}

Subjects were randomized to treatment using block randomization conducted at http://www.randomization.com/. There was equal probability to receive $0.9 \%$ saline or Plasma-lyte on the first study visit.

\subsection{Recruitment}

Healthy volunteers were recruited by advertising in public institutions and private companies in period 1 April 2015 to 31. January 2016.

\subsection{Subjects}

\section{Inclusion criteria}

Healthy, adult male volunteers between 18 and 45 year, with BMI between $18.5-30 \mathrm{~kg} / \mathrm{m}$.

\section{Exclusion criteria}

Arterial hypertension (blood pressure $140 \mathrm{mmHg}$ systolic and/or $>90 \mathrm{mmHg}$ diastolic), history or clinical signs of neoplastic disease or disease of the heart, lungs, kidneys or endocrine organs, drug or alcohol abuse (i.e. >14 units a week), significant abnormalities in laboratory screening test (i.e. abnormal hemoglobin, white cell count, plasma sodium, plasma potassium, plasma creatinine, plasma alanine aminotransferase, serum cholesterol, plasma bilirubin and plasma albumin, and urine samples (i.e. albuminuria or glucosuria), abnormal electrocardiogram.

Withdrawal criteria were development of one or more of the exclusion criteria or lack of compliance.

\subsection{Effect Variables}

Glomerular filtration rate (GFR), renal plasma flow (RPF) and filtration fraction (FF) obtained by $99 \mathrm{mTc}$-DTPA renography.

\subsection{Number of Subjects}

Fifteen healthy subjects were included. The sample size was calculated based on a minimally relevant difference in renal plasma flow (RPF) of $50 \mathrm{ml} / \mathrm{min}$ (about $10 \%$ ) and expected standard deviation of $67 \mathrm{ml} / \mathrm{min} \mathrm{[19],} \alpha=5 \%, \beta=20 \%$.

\subsection{Treatment Intervention}

0.9\% Sodium chloride Baxter A7S and Plasma-lyte Baxter A/S were provided by Herning Hospital Pharmacy (Table 1).

\subsection{Ethics}

This study was approved by The Central Denmark Region Committees on Healthy Research Ethics (case number: 1-16-02-264-15). The study was conducted in accordance with principles of declaration of Helsinki. Written informed consent was obtained from all subjects. 
Table 1. Characteristics of the 2 crystalloid infusions.

\begin{tabular}{ccc}
\hline & $0.9 \%$ saline & Plasma-lyte 148 \\
\hline Sodium $(\mathrm{mmol} / \mathrm{L})$ & 154 & 140 \\
Chloride $(\mathrm{mmol} / \mathrm{L})$ & 154 & 98 \\
Potassium $(\mathrm{mmol} / \mathrm{L})$ & - & 5 \\
Magnesium $(\mathrm{mmol} / \mathrm{L})$ & - & 1.5 \\
Acetate $(\mathrm{mmol} / \mathrm{L})$ & - & 27 \\
Gluconate $(\mathrm{mmol} / \mathrm{L})$ & - & 23 \\
Strong ion difference & 0 & 50 \\
$\mathrm{pH}$ & 5.4 & 7.4 \\
Theoretical osmolarity $(\mathrm{mOsm} / \mathrm{L})$ & 308 & 294.5 \\
Total solute weight $(\mathrm{g} / \mathrm{L})$ & 9 & 14.6 \\
Na: CL ratio & $1: 1$ & $1.43: 1$ \\
\hline
\end{tabular}

\subsection{Interventions/Experimental Procedure}

The study took place at The University Clinic of Nephrology and Hypertension, and Dept. of Nuclear Medicine, Regional Hospital West Jutland, Denmark in period 1, April 2015 to 31, January 2016. Participants met at 7.30 hours following a fast from midnight, after having abstained from alcohol and caffeine (24 hours). They did not eat or drink for the duration of the study. After voiding, height, weight and blood pressure was measured. After randomization, two 1-L bags of $0.9 \%$ saline or Plasma-Lyte 148 (Table 1) were infused over 1 hour using 2 MRI-compatible infusion pumps (Cardinal Health, Asena GW). Measurements of body weight and blood pressure were repeated at the end of the infusion. Within $15 \mathrm{~min}$ after completion of infusion, the renography was initiated. Participants were permitted to void as needed and, in all cases, at the end of infusion before and after the renography. The time of each micturition was noted, and urine volume after renography was measured.

\subsection{Measurements/Renography Protocol}

The kidney parameters (RPF, FF and GFR) were estimated from renographies obtained by a single-headed gamma camera (Bodyscan; MiE medical imaging electronics, Seth, Germany) in the posterior position over the lower thoracic/upper abdominal area with the patient in the supine projection. At the time of the bolus injection (6 MBq Tc99m-diethylenetriaminepentaacetic acid (DTPA)/kg bodyweight in a cubital vein), a dynamic acquisition was initiated (1 frame per second in the first minute and 1 frame per every 10 seconds during the subsequent 20 minutes).

Data processing was performed in the commercial software MEDIC 2000 XP, ver. 5.9.1. GFR, FF and RPF were calculated for each kidney separately and the single-kidney results summarised to create the total renal parameters.

The clearance of DTPA approaches GFR because the tracer is excreted almost 
exclusively by free filtration. Hence, single-kidney GFR was calculated from the uptake index in each kidney 60 - 120 seconds after the bolus injection using a modification of the Rutland-Patlak method [20].

RPF was calculated as the ratio of GFR, determined as described above, and FF of DTPA estimated from the first passage through the kidney approximately 10 - 45 seconds after the bolus injection. In this time interval, the software estimated FF by comparing the background corrected kidney activity with the calculated activity from the convolution integral, minimizing the sum of squared differences using an iterative approach. The analyses were performed by two nuclear medicine physicians blinded to knowledge of whether the patient had received Saline or Plasmolyte.

\subsection{Statistics}

Students paired $t$ test was used to compare the two groups, with significant difference at $P<0$. 05. We performed statistical analyses by using IBM SPSS statistics version 20.0.0 (SPSS Inc., Chicago, IL, USA) and STATA statistical software.

\section{Results}

\subsection{Demographics}

Fifteen males with a median age of 26 year (range 18 - 46 years), body mass index of $24.5 \pm 3 \mathrm{~kg} / \mathrm{m}^{2}$, P-creatinine of $82 \pm 8 \mu \mathrm{mol} / \mathrm{L}$, office systolic BP of $130 \pm 9$ $\mathrm{mmHg}$ and diastolic BP of $68 \pm 7 \mathrm{mmHg}$ completed the study. P-potassium was $3.8 \pm 0.2 \mathrm{mmol} / \mathrm{L}, \mathrm{P}$-sodium $140 \pm 3 \mathrm{mmol} / \mathrm{L}$ and hemoglobin $9.5 \pm 8 \mathrm{mmol} / \mathrm{L}$. All had normal renograms. None reported adverse effects.

\subsection{Changes in Body Weight and Blood Pressure}

There were no statistically significant differences between mean systolic and diastolic blood pressure (BP) before and after each infusion except baseline diastolic BP. Weight changes ( $\Delta$ weight) were similar after each infusion (Table 2).

\subsection{Renal Parameters}

Mean glomerular filtration rate GFR, renal plasma flow $(R P F)$ and filtration fraction $(F F)$ :

99-mTc-DTPA renography showed reduction in both mean GFR (114 \pm 13 $\mathrm{ml} / \mathrm{min}$ vs. $119 \pm 12 \mathrm{ml} / \mathrm{min}, p=0.04)$ and $\mathrm{RPF}(977 \pm 272 \mathrm{ml} / \mathrm{min}$ vs. $1066 \pm$

Table 2. Body weight and blood pressure baseline and after intervention.

\begin{tabular}{|c|c|c|c|c|c|c|c|}
\hline \multirow[t]{2}{*}{ Intervention } & \multicolumn{2}{|c|}{$\begin{array}{c}\text { Mean BP baseline } \\
(\mathrm{mmHg})\end{array}$} & \multicolumn{2}{|c|}{$\begin{array}{c}\text { Mean BP after } \\
(\mathrm{mmHg})\end{array}$} & \multirow{2}{*}{$\begin{array}{c}\text { Mean } \\
\text { weight } \\
\text { baseline }(\mathrm{kg})\end{array}$} & \multirow{2}{*}{$\begin{array}{c}\text { Mean } \\
\text { weight } \\
\text { after }(\mathrm{kg})\end{array}$} & \multirow{2}{*}{$\begin{array}{c}\Delta \\
\text { weight } \\
(\mathrm{kg})\end{array}$} \\
\hline & Systolic & Diastolic & Systolic & Diastolic & & & \\
\hline Plasma-lyte & $131 \pm 9$ & $70 \pm 8$ & $125 \pm 7$ & $66 \pm 6$ & $82 \pm 14$ & $83.3 \pm 15$ & $1.9 \pm 0.4$ \\
\hline $0.9 \%$ saline & $129 \pm 11$ & $66 \pm 7$ & $126 \pm 8$ & $66 \pm 8$ & $82.1 \pm 14$ & $83.1 \pm 14$ & $1.9 \pm 0.2$ \\
\hline$P$ value & 0.11 & 0.023 & 0.46 & 0.89 & 0.93 & 0.46 & 0.96 \\
\hline
\end{tabular}


$197 \mathrm{ml} / \mathrm{min}, p=0.19)$ and increasing FF (12\% $\pm 2 \%$ vs. $11 \% \pm 2 \%, p=0.19)$ after $0.9 \%$ saline comparing to Plasma-lyte, but only GFR reduction was statistically significant (Table 3).

Changes in GFR, RPF and FF after $0.9 \%$ saline versus Plasma-lyte in each subject.

Figures 1-3 show individual changes in GFR, RPF and FF after $0.9 \%$ saline and Plasma-lyte respectively. Reduction in GFR and RPF and increasing in FF after $0.9 \%$ saline was observed in 10 subjects while in 5 others reverse trend was shown.

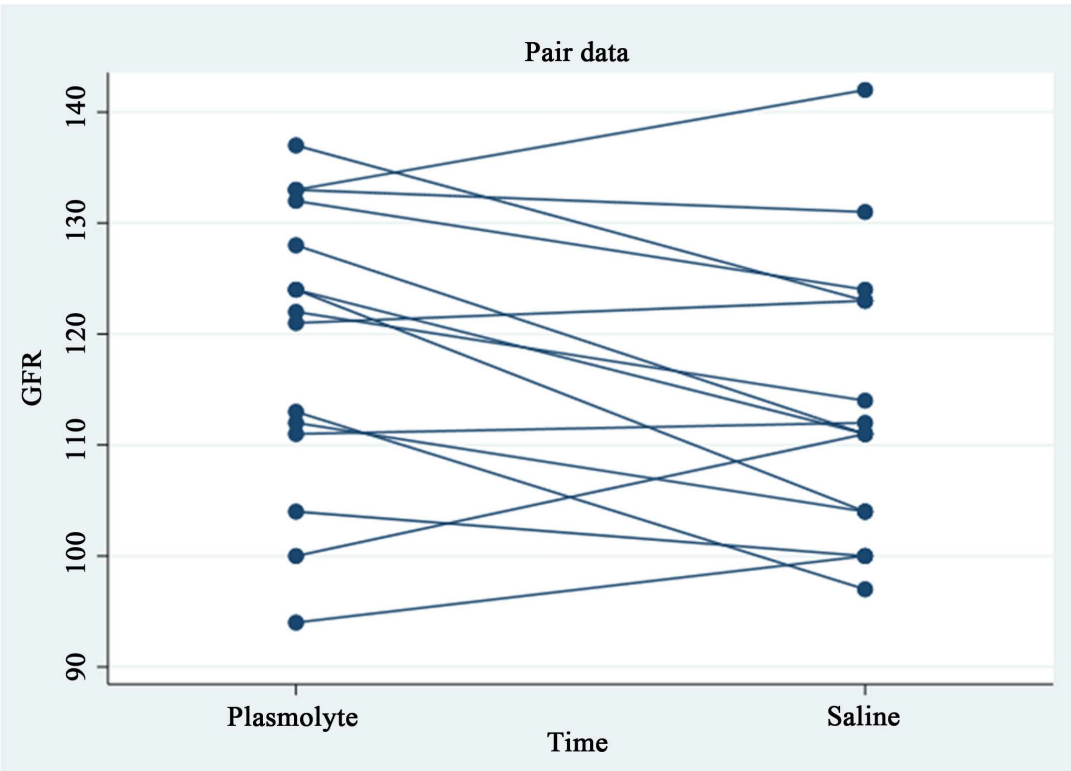

Figure 1. Changes in GFR after $0.9 \%$ saline versus Plasma-lyte in each subject.

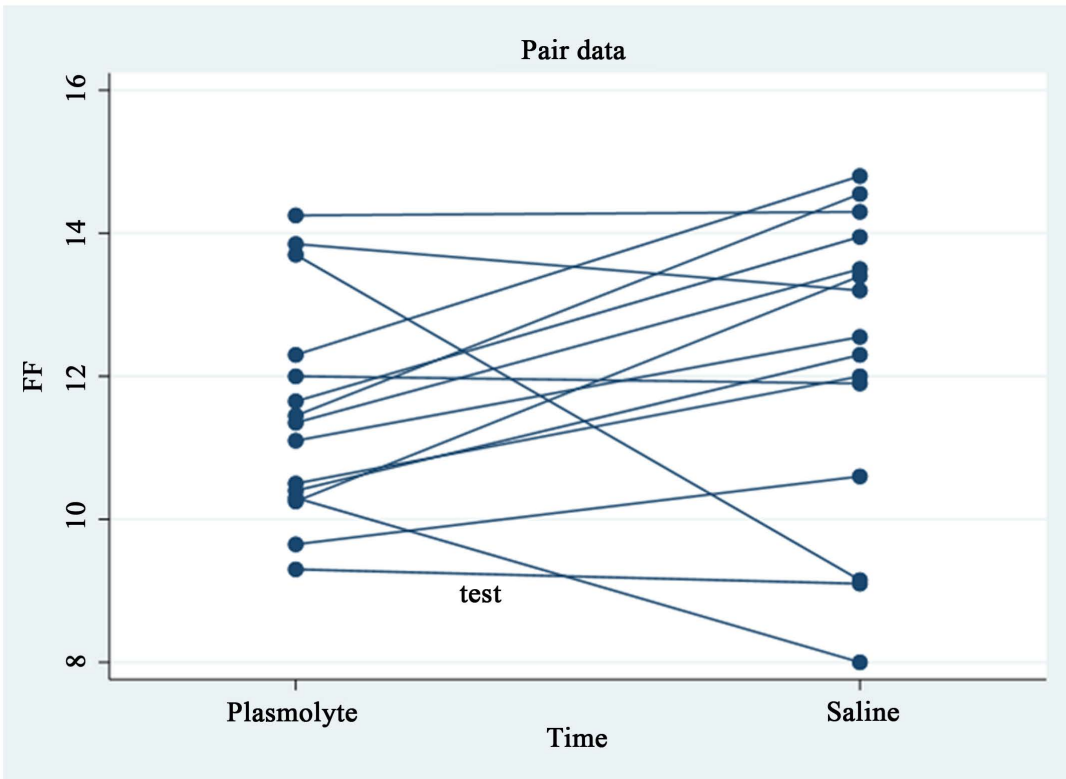

Figure 2. Changes in FF after $0.9 \%$ saline versus Plasma-lyte in each subject. 


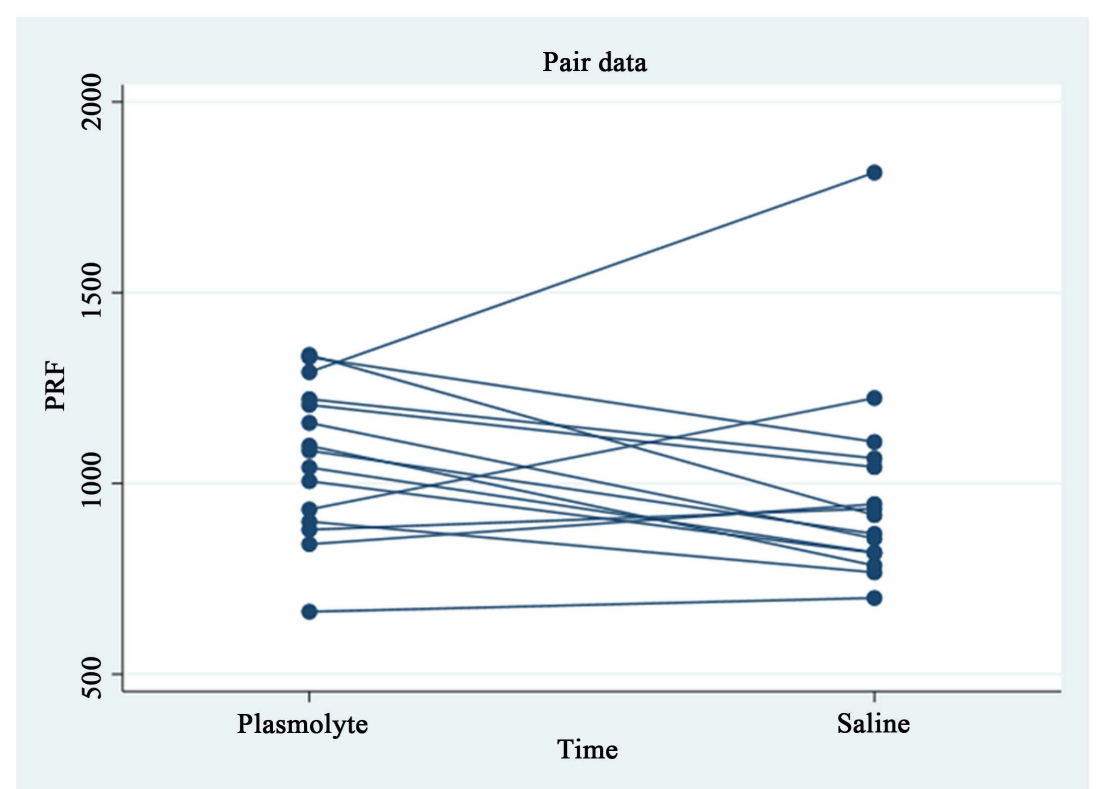

Figure 3. Changes in RPF after 0.9\% saline versus Plasma-lyte in each subject.

Table 3. Mean glomerular filtration rate GFR, renal plasma flow (RPF) and filtration fraction (FF) after Plasma-lyte and $0.9 \%$ saline.

\begin{tabular}{cccccc}
\hline & \multicolumn{2}{c}{ Plasma-lyte $(\mathrm{n}=15)$} & \multicolumn{2}{c}{$\mathbf{0 . 9 \%}$ saline $(\mathrm{n}=15)$} & \\
\cline { 2 - 5 } & Mean & SD & Mean & SD & \\
\hline GFR (ml/min) & 119 & 12 & 114 & 13 & $P=0.04$ \\
RPF (ml/min) & 1066 & 197 & 977 & 272 & $P=0.19$ \\
FF (\%) & 11 & 2 & 12 & 2 & $P=0.19$ \\
\hline
\end{tabular}

\section{The inter-and intra-assey variation coefficient for GFR, RPF and FF.}

The inter-and intra-assay variation coefficient was calculated as $\mathrm{SD} / \mathrm{X} * 100$ where $\mathrm{X}$ is mean value of GFR, RPF and FF and SD denotes standard deviation. The inter-assay variation coefficient for GFR was 10\% after Plasma-lyte and $11 \%$ after $0.9 \%$ saline; for RPF was $18 \%$ after Plasma-lyte and $28 \%$ after $0.9 \%$ saline; for FF was $18 \%$ after Plasma-lyte and $24 \%$ after $0.9 \%$ saline.

\section{Discussion}

We found a slight, but significant, impairment in GFR after saline-infusion compared to Plasmolyte. The impact of saline on FF and RPF are not significant but apart from two outlayers there is a tendency. Our findings support the existing data that the chloride overload from to $0.9 \%$ saline infusion, affects renal hemodynamics and may have negative effect on renal function. Such a hypothesis has been suggested in previous animal and human studies.

In the 1980s Wilcox et al. [4] have shown that intrarenal infusion of chloride solution $\left(0.9 \%\right.$ saline, $\left.\mathrm{NH}_{4} \mathrm{Cl}\right)$ in dogs led to decreased renal plasma flow and GFR because of renal chloride-induced vasoconstriction. Another study demonstrated that lowering the luminal chloride concentration reduced renal vascular 
responsiveness to angiotensin II, vasopressin and phenylephrine in rats [21]. A later study conducted by a Danish group in rabbits has also indicated that in the absence of chloride, the vasoconstrictive effects of angiotensin II and potassium were abolished [5] and that K-induced contraction of smooth muscle cells in the renal afferent arteriole is strongly chloride-dependent [6]. Some data indicate that chloride transport through macula densa is involved in tubuloglomerular feedback and increased chloride delivery to the distal nephron leads to decreased GFR [22]. Furthermore chloride infusion may induce vasoconstriction related to thromboxane release [7]. Altogether these data indicate an essential role of chloride in regulation of vascular resistance (primary afferent arteriole) and renal microcirculation and suggest that disturbances in chloride balance can affect kidney function.

The negative effect of chloride overload in the form of $0.9 \%$ saline infusion on kidney hemodynamics has been confirmed by human studies. In healthy volunteers intravenous infusion of $0.9 \%$ saline results in hyperchloremia and unfavorable changes in renal cortical perfusion measured using magnetic resonance imaging compared to Plama-lyte [3].

Our study results from healthy volunteers are in line with the negative effect of Chloride on kidney function as we detected a significant decrease in glomerular filtration rate and a subtle decrease in renal plasma flow after $0.9 \%$ saline infusion compared to Plasmolyte. The non-significant results for RPF rely on the two subjects in whom RPF increased excessively after Saline (Figure 3). This paradoxical response could not be explained technically, but may very well reflect the sensitive but indirect, and therefore quite imprecise estimation of RPF. Exclusion of those two subjects from statistical analysis rendered the changes in RPF highly significant $(p=0.002)$. Furthermore, the lack of significant drop in RPF after $0.9 \%$ saline could be due to too few study subjects as the SD for RPF used in the power calculation was much lower than observed in the study. Another issue that may affect results of our study is differences in the intra-assay variation for RPF of $18 \%$ after Plasma-lyte versus $28 \%$ after $0.9 \%$ saline. This reflects the sensitive but imprecise estimates of quantitative data from renography.

Despite these preclusions, our results support the hypothesis that using low chloride fluids could be associated with more favorable renal outcomes. We were focused on changes in GFR, FF and RPF and did not measure biochemical parameters during the study. Hence, the mechanism by which cloride affects renal haemodynamics cannot be elucidated further from our data.

It should be clarified that, as the study subjects were healthy males, the conclusion is limited to this population and may not be directly extrapolated to critically ill patients or females.

The importance of these findings in clinical practice remains unclear. Observational studies have shown that the use of chloride-restrictive intravenous fluid strategy was associated with better renal outcomes in critically ill and surgical patients [11] [12] [13] [23] although large randomized controlled trials show conflicting results. The SPLIT study [16] did not show significant decrease in the 
incidence of acute kidney injury after $0.9 \%$ saline infusion versus Plasma-lyte among patients in the intensive care unit. On the contrary, a recent, randomized study (SMART) have shown that use of balanced crystalloids (Plasma-lyte og lactated Ringer's solution) as intravenous fluid treatment had favorable effect on the composite outcome of death and major adverse kidney events compared with $0.9 \%$ saline in critically ill patients [17]. Published at the same time, SALT-ED study in patients hospitalized outside an ICU has demonstrated results consistent with SMART study [18]. The conclusions from large clinical studies are not equivocal, however, and it should be pointed out, that the studies were heterogeneous both regarding patient populations and the interventions, especially infused fluid volumes, which may significantly affect the results.

\section{Strengths and Limitations}

The major strength of the study is the strong study design (randomized, crossover-controlled, single-blind trial). Only men were included to eliminate sex differences.

Furthermore, the study conditions were standardized regarding food and water intake, coffeine and alcohol consumption to avoid any confounding of the results. The crossover design minimizes the effect of other confounders such as smoking and anatomical conditions.

Ideally, renal haemodynamics should be measured from infusion techniques with double isotope technique with suitable tracers for GFR and RPF. Such a set up was not accessible in our institution at that time. DTPA fulfills the criteria for GFR measurements, but the use of this tracer to calculate RPF is cumbersome and imprecise which is reflected in the large SD intervals. The absolute calculated RPF values must be interpreted with precaution, but due to the cross-over design inter-individual variations are eliminated.

\section{Conclusion}

We have demonstrated that high chloride infusion can affect kidney function in healthy subjects and seems to lead to impairment in both RPF and GFR. Our results are consistent with previous preclinical and observational data. The clinical relevance of these observations in patients is unclear, especially in the light of recent large randomized controlled trials.

Further studies are needed to clarify this issue.

\section{Acknowledgements}

The authors thank our laboratory technicians, including Anne Mette Ravn, Henriette Vorup Simonsen and Kirsten Nyggard for their skillful assistance.

\section{Ethics Approval and Consent to Participate}

This study was approved by The Central Denmark Region Committees on Healthy Research Ethics (case number: 1-16-02-264-15). The study was con- 
ducted in accordance with principles of declaration of Helsinki. Written informed consent was obtained from all subjects.

\section{Consent for Publication}

Not applicable.

\section{Availability of Data and Materials}

The datasets used and analysed during the study are available from the corresponding author on reasonable request.

\section{Conflicts of Interest}

The authors declare that they have no competing interests.

\section{Author's Contributions}

All authors have contributed to the publication. A. E. Oczachowska-Kulik, M.H. Malmberg, J. J. Jensen and J. N. Bech designed the project. A. E. Oczachowska-Kulik and M.H. Malmberg performed the experiments. A. E. Oczachowska-Kulik, J. J. Jensen and J. A. Ejlersen performed laboratory analysis. A. E. Oczachowska-Kulik and J. A. Ejlersen performed statistical analysis. A. E. Oczachowska-Kulik, J. A. Ejlersen and J. N. Bech wrote and edited the manuscript.

\section{References}

[1] Burdett, E., Dushianthan, A., Bennett-Guerrero, E., et al. (2012) Perioperative Buffered versus Non-Buffered Fluid Administration for Surgery in Adults. Cochrane Database of Systematic Reviews, 12, CD004089. https://doi.org/10.1002/14651858.CD004089.pub2

[2] Kellum, J.A. (2004) Metabolic Acidosis in Patients with Sepsis: Epiphenoman or Part of the Pathophysiology? Critical Care \& Resuscitation, 6, 197-203.

[3] Chowdhury, A.H., Cox, E.F., Francis, S.T. and Lobo, D.N. (2012) A Randomized, Controlled, Double Blind Crossover Study on the Effects of 2-L Infusions of $0.9 \%$ Saline and Plasma-lyte ${ }^{\varpi} 148$ on Renal Blood Flow Velocity and Renal Cortical Tissue Perfusion in Healthy Volunteers. Annals of Surgery, 256, 18-24. https://doi.org/10.1097/SLA.0b013e318256be72

[4] Wilcox, C.S. (1983) Regulation of Renal Blood Flow by Plasma Chloride. Journal of Clinical Investigation, 71, 726-735. https://doi.org/10.1172/JCI110820

[5] Jensen, B.L. and Skøtt, O. (1997) Chloride Is Essential for Contraction of Afferent Arterioles after Agonists and Potassium. American Journal of Physiology, 272, F389-F396. https://doi.org/10.1152/ajprenal.1997.272.3.F389

[6] Hansen, P.B., Jensen, B.L. and Skott, O. (1998) Chloride Regulates Afferent Arteriolar Contraction in Response to Depolarization. Hypertension, 32, 1066-1070. https://doi.org/10.1161/01.HYP.32.6.1066

[7] Bullivant, E.M., Wilcox, C.S., Welch, W.J., Mary, E., Bullivant, A., Wilcox, C.S., et al. (1989) Intrarenal Vasoconstriction during Hyperchloremia: Role of Thromboxane. The American Journal of Physiology: Renal Physiology, 256, F152-F157. https://doi.org/10.1152/ajprenal.1989.256.1.F152 
[8] Kellum, J.A., Song, M. and Venkataraman, R. (2004) Effects of Hyperchloremic Acidosis on Arterial Pressure and Circulating Inflammatory Molecules in Experimental Sepsis. Chest, 125, 243-248. https://doi.org/10.1378/chest.125.1.243

[9] Kellum, J.A., Song, M. and Almasri, E. (2006) Hyperchloremic Acidosis Increases Circulating Inflammatory Molecules in Experimental Sepsis. Chest, 130, 962-967. https://doi.org/10.1378/chest.130.4.962

[10] McCluskey, S.A., Karkouti, K., Wijeysundera, D., Minkovich, L., Tait, G. and Beattie, W.S. (2013) Hyperchloremia after Noncardiac Surgery Is Independently Associated with Increased Morbidity and Mortality: A Propensity-Matched Cohort Study. Anesthesia \& Analgesia, 117, 412-421.

https://doi.org/10.1213/ANE.0b013e318293d81e

[11] Shaw, A.D., Bagshaw, S.M., Goldstein, S.L., et al. (2012) Major Complications, Mortality, and Resource Utilization after Open Abdominal Surgery: 0.9\% Saline Compared to Plasma-Lyte. Annals of Surgery, 255, 821-829. https://doi.org/10.1097/SLA.0b013e31825074f5

[12] Yunos, N.M., Bellomo, R., Hegarty, C., et al. (2012) Association between a Chloride Liberal vs. Chloride-Restrictive Intravenous Fluid Administration Strategy and Kidney Injury in Critically Ill Adults. JAMA, 308, 1566-1572. https://doi.org/10.1001/jama.2012.13356

[13] Krajewski, M.L., Raghunathan, K., Paluszkiewicz, S.M., et al. (2014) Meta-Analysis of High- versus Low-Chloride Content in Perioperative and Critical Care Fluid Resuscitation. British Journal of Surgery, 102, 24-36. https://doi.org/10.1002/bjs.9651

[14] Raghunathan, K., Shaw, A., Nathanson, B., et al. (2014) Association between the Choice of IV Crystalloid and In-Hospital Mortality among Critically Ill Adults with Sepsis. Critical Care Medicine, 42, 1585-1591. https://doi.org/10.1097/CCM.0000000000000305

[15] Shaw, A.D., Raghunathan, K., Peyerl, F.W., et al. (2014) Association between Intravenous Chloride Load during Resuscitation and In-Hospital Mortality among Patients with SIRS. Intensive Care Medicine, 40, 1966-1968. https://doi.org/10.1007/s00134-014-3505-3

[16] Young, P., Bailey, M., Beasley, R., et al. (2015) Effect of a Buffered Crystalloid Solution vs Saline on Acute Kidney Injury among Patients in the Intensive Care Unit: The SPLIT Randomized Clinical Trial. JAMA, 314, 1701-1710.

https://doi.org/10.1001/jama.2015.12334

[17] Semler, M.W., Self, W.H., Wanderer, J.P., et al. (2018) Balanced Crystalloids versus Saline in Criticaly Ill Adults. The New England Journal of Medicine, 378, 829-839. https://doi.org/10.1056/NEJMoa1711584

[18] Self, W.H., Semler, M.W., Wanderer, J.P., et al. (2018) Balanced Crystalloids versus Saline in Noncriticaly Ill Adults. The New England Journal of Medicine, 378, 819-823. https://doi.org/10.1056/NEJMoa1711586

[19] Madsen, C.J., Møller, M.L., Zerahn, B., Fynbo, C. and Jensen, J.J. (2013) Determination of Kidney Function with 99mTc-DTPA Renography Using a Dual-Head Camera. Nuclear Medicine Communications, 34, 322-327. https://doi.org/10.1097/MNM.0b013e32835f1620

[20] Petersen, J.L., Petersen, J.R., Talleruphuus, U., et al. (1999) Glomerular Filtration Rate Estimated from the Uptake Phase of 99mTc-DTPA Renography in Chronic Renal Failure. Nephrology Dialysis Transplantation, 14, 1673-1678. https://doi.org/10.1093/ndt/14.7.1673

[21] Quilley, C.P., Lin, Y.S. and McGiff, J.C. (1993) Chloride Anion Concentration as a 
Determinant of Renal Vascular Responsiveness to Vasoconstrictor Agents. British Journal of Pharmacology, 108, 106-110. https://doi.org/10.1111/j.1476-5381.1993.tb13447.x

[22] Salomonsson, M., Gonzalez, E., Kornfeld, M., et al. (1993) The Cytosolic Chloride Concentration in Macula Densa and Cortical Thick Ascending Limb Cells. Acta Physiologica Scandinavica, 147, 305-313. https://doi.org/10.1111/j.1748-1716.1993.tb09503.x

[23] Ashraf, N., Salahuddin, N., El Hazimi, A., et al. (2014) Chloride-Liberal Fluids Are Associated with Acute Kidney Injury after Liver Transplantation. Critical Care, 18, 625.

\section{List of Abbreviations}

BP: Blood Pressure, eGFR: estimated Glomerular Filtration Rate, RPF: Renal Plasma Flow, FF: Filtration Fraction, 99-mTc-DTPA: Technetium-99m Diethylenetriamine Penta-Acetic acid, SD: Standard Deviation. 